\title{
Jejunal Band
}

National Cancer Institute

\section{Source}

National Cancer Institute. Lejunal Band. NCI Thesaurus. Code C101277.

A pathologic fibrous band that impedes passage of intestinal contents through the jejunum. 